\title{
LETTER
}

\section{The utility of the SOFA score for predicting mortality in critically ill cirrhotic patients receiving liver transplantation}

\author{
Kama Wlodzimirow* and Ameen Abu-Hanna \\ See related research by Karvellas et al., http://ccforum.com/content/17/1/R28/abstract
}

Karvellas and colleagues [1] conducted a multi-center retrospective cohort study to examine, among other things, the prognostic value of the Sequential Organ Failure Assessment (SOFA) score for predicting 90-day mortality in critically ill cirrhotic patients receiving liver transplantation. They conclude that the SOFA score at admission, at 48 hours and at liver transplantation was not independently associated with the outcome. This association could potentially play a role in future predictive models, although such models will be restricted to patients for which transplantation decisions would have already been made.

In our systematic review [2] we noted the usefulness of predictors of mortality that were based on changes in the SOFA (sub)scores over time. Changes in (other) variables were also recently attempted in an acute liver failure cohort [3] and their added prognostic value was shown. It might have been useful to investigate in the study of Karvellas and colleagues [1] the utility of such SOFArelated changes (including organ failure patterns [4]), although the missing values (for example, $44 \%$ at 48 hours) would have imposed an even larger problem. Imputation (for example, based on values on adjacent days) may perhaps mitigate this problem.

In addition, although the goal in the study of Karvellas and colleagues [1] is not to develop a new prediction model per se, it would have been informative to report on validation (internal, temporal and/or external) using various performance measures such as the area under the (receiver operating characteristic) curve (AUC) and the
Brier score as recommended by the assessment framework used in [5].

Perhaps the SOFA-score deserves a second chance after all.

\section{Abbreviations}

SOFA, Sequential Organ Failure Assessment.

\section{Competing interests}

The authors declare that they have no competing interests.

Published: 16 April 2013

\section{References}

1. Karvellas CJ, Lescot T, Goldberg P, Sharpe MD, Ronco JJ, Renner EL, Vahidy H, Poonja Z, Chaudhury P, Kneteman NM, Selzner M, Cook EF, Bagshaw SM, and the Canadian Liver Failure Study Group: Liver transplantation in the critically ill: a multi-centre Canadian retrospective cohort study. Crit Care 2013, 17:R28.

2. Minne L, Abu-Hanna A, de Jonge E: Evaluation of SOFA-based models for predicting mortality in the ICU: A systematic review. Crit Care 2008, 12:R161.

3. Kumar R, Shalimar, Sharma H, Goyal R, Kumar A, Khanal S, Prakash S, Gupta SD, Panda SK, Acharya SK: Prospective derivation and validation of early dynamic model for predicting outcome in patients with acute liver failure. Gut 2012, 61:1068-1075.

4. Toma T, Bosman RJ, Siebes A, Peek N, Abu-Hanna A: Learning predictive models that use pattern discovery--a bootstrap evaluative approach applied in organ functioning sequences. J Biomed Inform 2010, 43:578-586.

5. Wlodzimirow KA, Eslami S, Chamuleau RAFM, Nieuwoudt M, Abu-Hanna A: Prediction of poor outcome in patients with acute liver failure - Systematic review of prediction models. Plos One 2012, 7:e50952.

\section{doi:10.1186/cc12577}

Cite this article as: Wlodzimirow K, Abu-Hanna A: The utility of the SOFA score for predicting mortality in critically ill cirrhotic patients receiving liver transplantation. Critical Care 2013, 17:426.
*Correspondence: k.a.wlodzimirow@amc.uva.nl

Department of Medical Informatics, Academic Medical Center, University of

Amsterdam, Meibergdreef 15, 1105 AZ Amsterdam, The Netherlands 